\title{
SEI-forming electrolyte additives for lithium-ion batteries: development and benchmarking of computational approaches
}

\author{
Piotr Jankowski ${ }^{1,2,3}$ • Wladysław Wieczorek ${ }^{1,3}$ - Patrik Johansson 2,3,4 $^{\text {2, }}$ \\ Received: 26 September 2016 / Accepted: 28 November 2016/Published online: 13 December 2016 \\ (C) The Author(s) 2016. This article is published with open access at Springerlink.com
}

\begin{abstract}
SEI-forming additives play an important role in lithium-ion batteries, and the key to improving battery functionality is to determine if, how, and when these additives are reduced. Here, we tested a number of computational approaches and methods to determine the best way to predict and describe the properties of the additives. A wide selection of factors were evaluated, including the influences of the solvent and lithium cation as well as the DFT functional and basis set used. An optimized computational methodology was employed to assess the usefulness of different descriptors.
\end{abstract}

Keywords SEI-forming additive $\cdot$ Lithium-ion battery . DFT $\cdot$ Benchmark $\cdot$ Reduction

This paper belongs to Topical Collection 7th Conference on Modeling \& Design of Molecular Materials in Trzebnica (MDMM 2016)

Electronic supplementary material The online version of this article (doi:10.1007/s00894-016-3180-0) contains supplementary material, which is available to authorized users.

Piotr Jankowski

pjankowski@ch.pw.edu.pl

1 Faculty of Chemistry, Warsaw University of Technology, ul. Noakowskiego 3, 00-664 Warsaw, Poland

2 Department of Physics, Chalmers University of Technology, SE-412 96 Gothenburg, Sweden

3 ALISTORE-ERI European Research Institute, 33 rue Saint Leu, 80039 Amiens, France

4 Laboratoire de Réactivité et Chimie des Solides, CNRS UMR 7314, Université de Picardie Jules Verne, 33 rue Saint Leu, 80039 Amiens, France

\section{Introduction}

While high-capacity lithium-ion batteries (LIBs) have dominated the market for storage devices since the end of the twentieth century, there is still a growing need for betterperforming batteries that can meet future energy demands [1-5]. The essential challenge is to develop a system with a much higher energy density than LIBs but which also at least matches LIBs in terms of cycle life. The stored energy is a product of the storage of charge in the electrodes (capacity) and the difference in potential between the electodes (voltage), and a popular way to improve the energy density is to increase the electrochemical potential difference between the cathode and anode. Since the potential of the commercially used anode, graphite, is already very close to the value for lithium metal $\left(0.1 \mathrm{~V} \mathrm{vs} \mathrm{Li}^{+} / \mathrm{Li}^{0}\right)$ [6], the focus is on developing cathode materials that enable potentials as high as $5 \mathrm{~V} \mathrm{vs.} \mathrm{Li}^{+} / \mathrm{Li}^{0}$ to be feasible [7]. However, such a large potential difference poses a significant challenge in terms of selecting an appropriate electrolyte to use in the cell. The thermodynamic stability of the electrolyte is defined by its highest occupied molecular orbital (HOMO) and lowest unoccupied molecular orbital (LUMO) energies. Usually, the electrolyte is chosen to match the cathode potential and to provide kinetic stability at the anode-electrolyte interface. Currently applied electrolytes, based on mixtures of organic carbonates, undergo reduction processes at ca. $1 \mathrm{~V} \mathrm{vs.} \mathrm{Li}^{+} / \mathrm{Li}^{0}$ with the formation of a passivation layer - the solid electrolyte interphase (SEI). The SEI layer limits further reduction of the electrolyte and also affects many important battery parameters such as the capacity fade and power density. A spontaneously formed SEI causes a significant reduction in battery capacity, which is further worsened by subsequent charge-discharge cycles, so the application of a "functional" electrolyte is recommended [8]. Such an electrolyte consists of salt(s), solvent(s), and special 


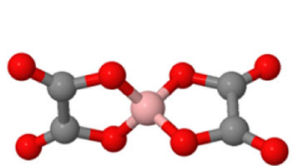

BOB
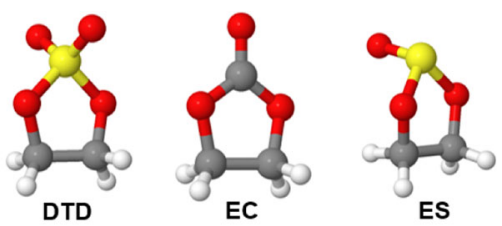

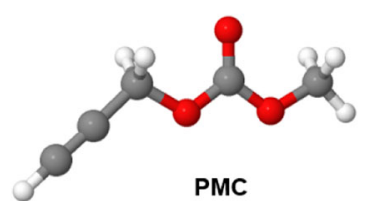

PMC
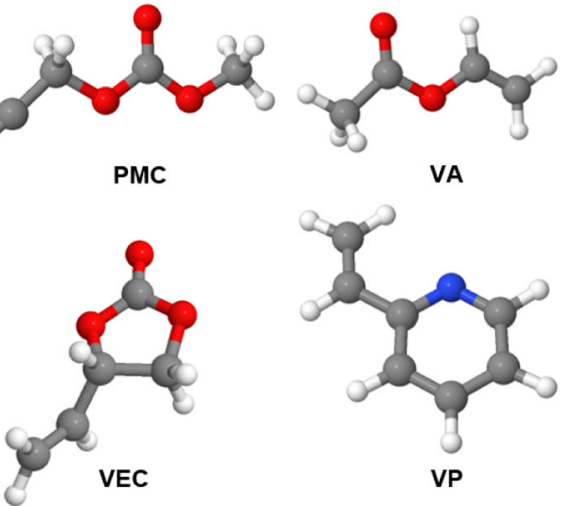

VA

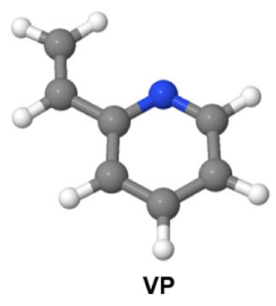

Fig. 1 Chemical structures of the SEI-forming additives; all geometries were optimized using C-PCM M06-2X/6-311++G(d,p)

functional additives; whereof SEI-forming additives are responsible for the controlled and rapid creation of an SEI layer.

SEI-forming additives have two main features: "high" reduction potentials and decomposition paths toward structures that can enable cation conduction between the anode and the electrolyte, such as oligo- or polymeric molecules similar to polymer electrolytes. There are a few groups of compounds that are known to fulfill these requirements. (i) Molecules containing unsaturated carbon-carbon bonds that provide an easy route for polymerization under reducing conditions. The most popular of these - vinyl carbonate (VC) — is able to form both types of polymeric species: poly(VC) and oligomers of VC [9-13]. Other compounds such as vinylethylcarbonate (VEC) [10, 14] and propargylmethyl carbonate (PMC) [15, 16] also effectively restrain the decrease in capacity. (ii)
Molecules with halogen atoms such as fluorinated (FEC) [17] and chlorate carbonates (CEC) [18]. In these, the presence of the electronegative atom successfully initiates SEI creation, although the SEIs are usually more resistant and comprise various inorganic salts ( $\mathrm{LiF}, \mathrm{LiCl}$ ). (iii) Sulfurbased compounds, mostly with structures similar to carbonates, such as organic sulfonates, sulfites, and sulfates. Ethylene sulfite (ES), the analog of EC, is very easily reduced at ca. $2 \mathrm{~V} \mathrm{vs}$. $\mathrm{Li}^{+} / \mathrm{Li}^{0}$, but the main product of its degradation is inorganic $\mathrm{Li}_{2} \mathrm{SO}_{3}$. Better properties may be obtained by using 1,3,2-dioxathiolane-2,2-dioxide (DTD), as the creation of a polymeric structure has been observed in this case [19, 20].

Computational studies are a popular means to develop better-performing additives, as they are faster and much less expensive than experimental trial-and-error testing. Many such studies have focused on explaining the reduction mechanisms associated with SEI formation, mainly for carbonate compounds such as EC, DMC, and VC [21-28], via a homolytic ring-opening mechanism. Less attention has been directed into the study of, for example, sulfur-containing compounds [29-31]. However, the most effective way to develop new additives appears to be computational screening [32-34], which involves focusing on specific features connected to a few descriptors. Such descriptors significantly simplify analysis when a very large number of compounds are considered. They enable the characteristics of new derivatives to be predicted based on fundamental molecular parameters. The most commonly used descriptors are the LUMO energy, the electron affinity (EA), and the chemical hardness $(\eta)$. The first two describe the thermodynamic ability to accept a new electron and are used to assess the reduction potential, whereas $\eta$ is a measure of reaction resistance and can serve as an indicator of the kinetics. Halls and Tasaki showed that a small $\eta$ and low LUMO are favorable for SEI-forming additives [35]. Another couple of properties of importance were proposed by Park: the
Fig. 2a-c The three thermodynamic cycles - (a), (b), and (c) - used to calculate reduction potentials. As the change in energy of an electron upon switching from a vacuum to solution is very small, it was neglected (i.e., defined as exactly zero). $A$ denotes the additive
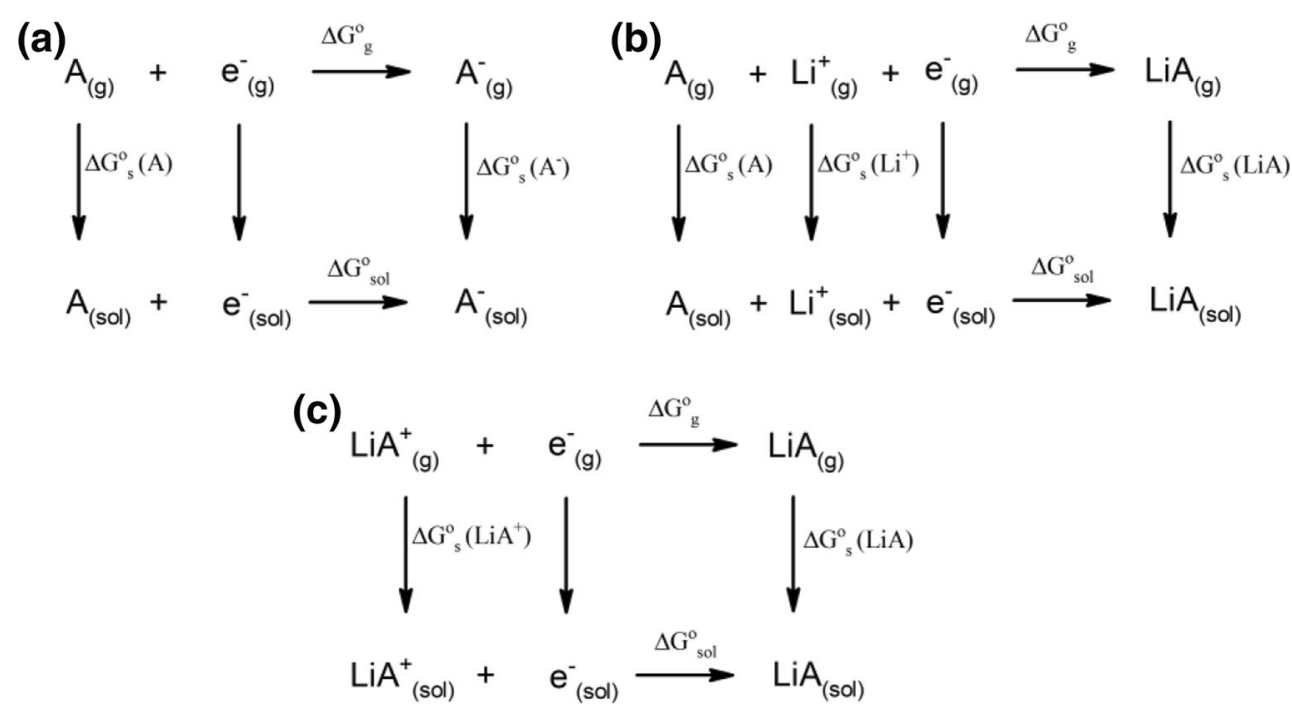
Table 1 Comparison of the dipole moments, HOMO and LUMO energies, ionization potentials, electron affinities, chemical hardnesses, binding energies, and reduction potentials determined using different dielectric constants in C-PCM and M06-2X/6-311++G(d,p) calculations

\begin{tabular}{|c|c|c|c|c|c|c|c|c|c|c|c|}
\hline & & \multicolumn{5}{|l|}{$\mathrm{EC}$} & \multicolumn{5}{|l|}{ DTD } \\
\hline & & $\begin{array}{l}\text { Vacuum } \\
\varepsilon_{\mathrm{r}}=1\end{array}$ & $\begin{array}{l}\text { THF } \\
\varepsilon_{\mathrm{r}}=7.4\end{array}$ & $\begin{array}{l}\text { Acetone } \\
\varepsilon_{\mathrm{r}}=20.5\end{array}$ & $\begin{array}{l}\mathrm{ACN} \\
\varepsilon_{\mathrm{r}}=35.7\end{array}$ & $\begin{array}{l}\text { Water } \\
\varepsilon_{\mathrm{r}}=78.4\end{array}$ & $\begin{array}{l}\text { Vacuum } \\
\varepsilon_{\mathrm{r}}=1\end{array}$ & $\begin{array}{l}\text { THF } \\
\varepsilon_{\mathrm{r}}=7.4\end{array}$ & $\begin{array}{l}\text { Acetone } \\
\varepsilon_{\mathrm{r}}=20.5\end{array}$ & $\begin{array}{l}\mathrm{ACN} \\
\varepsilon_{\mathrm{r}}=35.7\end{array}$ & $\begin{array}{l}\text { Water } \\
\varepsilon_{\mathrm{r}}=78.4\end{array}$ \\
\hline \multicolumn{2}{|l|}{$\mu(\mathrm{D})$} & 5.62 & 7.06 & 7.25 & 7.30 & 7.33 & 6.01 & 7.66 & 7.88 & 7.94 & 7.98 \\
\hline \multicolumn{2}{|l|}{ HOMO (eV) } & -10.45 & -10.61 & -10.62 & -10.62 & -10.62 & -10.75 & -10.77 & -10.77 & -10.77 & -10.77 \\
\hline \multicolumn{2}{|l|}{ LUMO (eV) } & -0.38 & 0.02 & 0.05 & 0.05 & 0.06 & -0.46 & 0.00 & 0.03 & 0.04 & 0.04 \\
\hline \multicolumn{2}{|l|}{ IP $(e V)$} & 11.44 & 9.68 & 9.47 & 9.41 & 9.38 & 11.83 & 9.82 & 9.63 & 9.63 & 9.55 \\
\hline \multicolumn{2}{|l|}{$\mathrm{EA}(\mathrm{eV})$} & -1.06 & 0.43 & 0.58 & 0.62 & 0.65 & -0.48 & 0.36 & 0.55 & 0.61 & 0.65 \\
\hline \multicolumn{2}{|l|}{$\eta(\mathrm{eV})$} & 6.25 & 4.63 & 4.44 & 4.40 & 4.36 & 6.15 & 4.73 & 4.54 & 4.51 & 4.45 \\
\hline \multicolumn{2}{|l|}{$\mathrm{BE}\left(\mathrm{kJ} \mathrm{mol}^{-1}\right)$} & 209.5 & 38.64 & 22.29 & 18.64 & 15.97 & 180.22 & 26.11 & 12.23 & 9.57 & 7.43 \\
\hline \multirow[t]{4}{*}{$E_{\text {red }}\left(\mathrm{V}\right.$ vs. $\left.\mathrm{Li}^{+} / \mathrm{Li}^{0}\right)$} & $\mathrm{a}$ & -1.11 & 0.97 & 1.18 & 1.23 & 1.27 & -1.87 & 1.58 & 1.85 & 1.90 & 1.94 \\
\hline & $\mathrm{b}$ & 5.85 & 2.15 & 1.78 & 1.70 & 1.64 & 6.34 & 2.70 & 2.34 & 2.31 & 2.19 \\
\hline & $\mathrm{c}$ & 3.80 & 1.90 & 1.71 & 1.67 & 1.64 & 4.60 & 2.55 & 2.33 & 2.30 & 2.24 \\
\hline & Exp. & \multicolumn{5}{|l|}{1.36 [69] } & \multicolumn{5}{|l|}{2.13 [19] } \\
\hline
\end{tabular}

dipole moment $(\mu)$, and the binding energy with a lithium cation (BE). A higher $\mu$ leads to a stronger nonbonding interaction with $\mathrm{Li}^{+}$, whereas weak binding between the additive and the lithium cation facilitates processes on the anode and ensures rapid formation of the SEI [36]. In some cases, a sufficient change in bond length could also be a descriptor that predicts the vulnerability of a bond to the fragmentation of the additive during the reduction process [33].

To obtain trustworthy predictions for applications, it is crucial to apply a proper methodology, encompassing the selection of a method, model, and computational approach [37]. In 2004, Han tested several different DFT functionals with the aim of evaluating additive performance by describing the reduction of EC and VC [26]. However, since then there has been further progress in this area of research, including a new family of Minnesota functionals [38-41]. Several redoxprocess benchmarking papers have already been published which show that some functionals, especially M06-2X, provide better results than previously thought [42-45]. However, while they generally show improved performance as compared to wavefunction-based methods, it is essential to compare the results they yield to concrete experimental data for additives used in battery electrolytes in order to identify the best methodology. Another issue is how to include the effects of solvents: Lespes et al. [46] recommend the use of an implicit solvent model coupled with an explicit representation of the first solvation shell. However, as this approach is computational expensive, especially if there are a large number of molecules to be tested and their stable configurations are not known, implicit models are usually used. The type of solvent and its permeability (dielectric constant) applied in the model vary, as does the approach used to calculate the reduction potential (e.g., the effect of salt is the source of debate) $[27-29,47,48]$.
In the work reported in the present paper, we compared different ways of predicting reduction behavior using a methodological benchmark. Various basis sets, DFT functionals, and solvation models were tested. Finally, a methodology was chosen, and a search for appropriate descriptors was conducted. All of the data were generated for several well-known SEI-forming additives (EC, FEC, VC, VEC, PMC, vinyl acetate (VA) [16], 2-vinyl pyridine (VP) [49], ES, DTD, and BOB; Fig. 1), enabling us to correlate the chosen methodology with corresponding experimental data.

\section{Computational details}

All calculations were carried out with the Gaussian09 package [50] using Hartree-Fock (HF) and several DFT functionals: mPW2PLYP [51], TPSSh [52], B2PLYP [53], B3LYP [54], VSXC [55], PBE0 [56], M06-2X [39], M06L [57], M11 [40], and MN12L [41]. Four triple-zeta basis sets with polarization and diffuse functions from different families were tested: 6311++G(d,p) [58, 59], def2-TVPD [60], aug-pcseg-2 [61], and aug-cc-pVTZ [62]. The influence of solvent was examined using the conductor-variant polarized continuum model (C-PCM) [63, 64] with the M06-2X functional. Tetrahydrofuran $(\mathrm{r}=7.4)$, acetone $(\mathrm{r}=20.5)$, acetonitrile $(r=35.7)$, and water $(r=78.4)$ were employed as model solvents. All of the geometries were optimized both in vacuum and in each of the solvents tested. The reduction potentials were calculated in three different ways using thermodynamic cycles (Fig. 2): (a) ignoring the influence of the lithium cation, (b) assuming the simultaneous reduction and coordination of the lithium cation (electroneutrality); and (c) assuming that the lithium cation is coordinated to the molecule during the entire reduction process. A correction of $-1.46 \mathrm{~V}$ was used to 
(a)

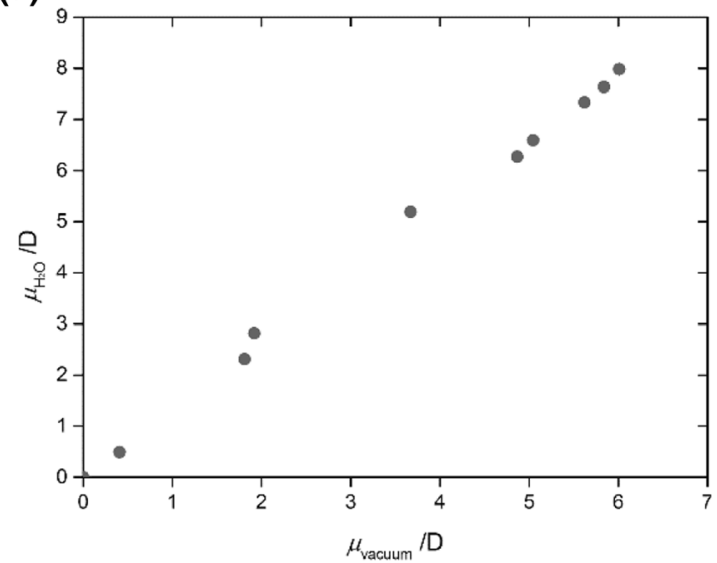

(c)

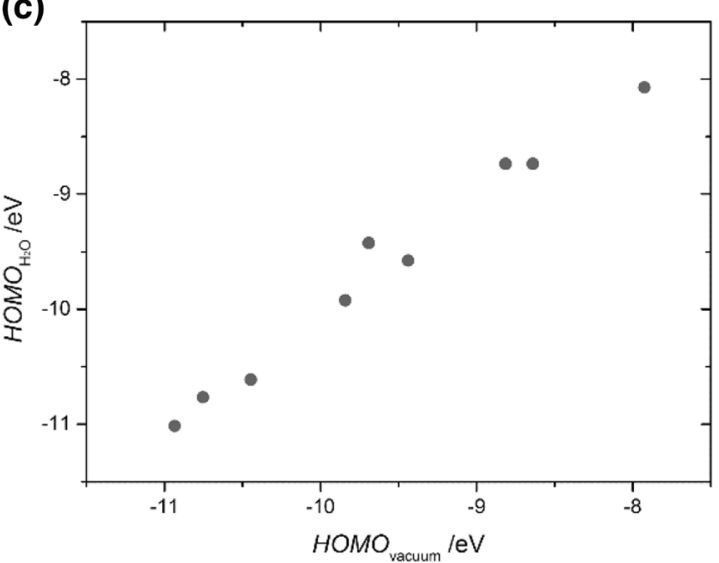

(b)

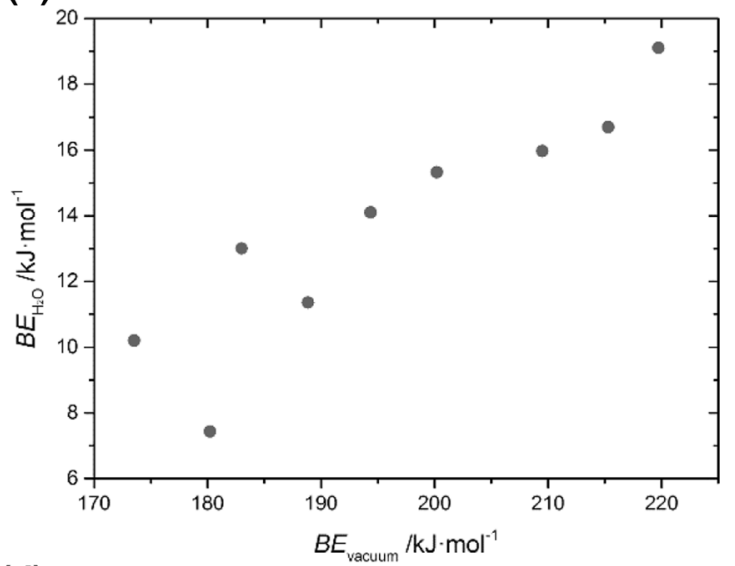

(d)

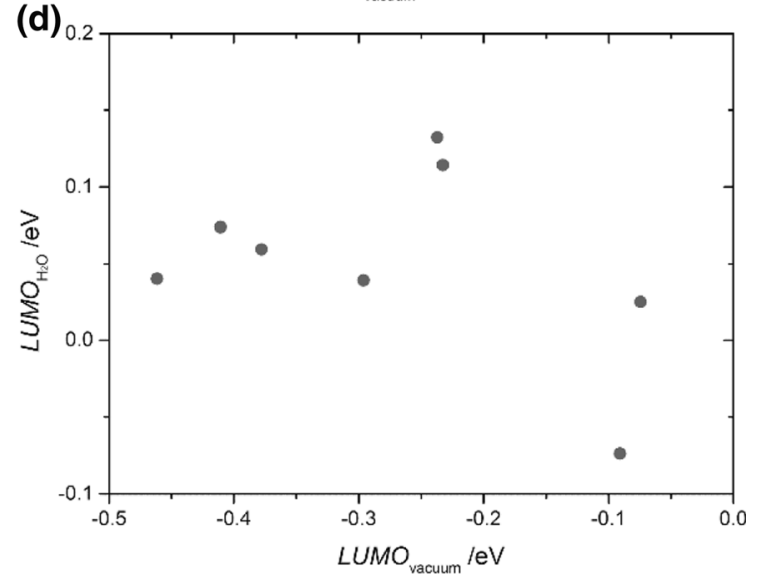

Fig. 3a-d Comparison of dipole moments (a), BEs (b), HOMO energies (c), and LUMO energies (d) calculated in the gas phase and by C-PCM (in water)

convert absolute potentials to the $\mathrm{Li}^{+} / \mathrm{Li}^{0}$ scale [65]. Additionally, several descriptors ( $\mu$, HOMO, LUMO, IP, $\mathrm{EA}, \eta$, and $\mathrm{BE}$ ) were determined for each additive, based on the optimized ground-state structure. $\mathrm{A}-\mathrm{Li}^{+}$ion-pair complexes were obtained by optimizing the starting geometries generated by the random insertion of $\mathrm{Li}^{+}$at 25 different positions relative to each choice of A.

\section{Results and discussion}

We performed our benchmarking in three steps: first, we tested the effects of varying the solvent model and the dielectric constant; second, for a chosen solvation mode, we carried out DFT and basis set benchmarking; finally, using the bestperforming methodology, we searched for descriptors that could enhance the computational screening of SEI-forming additives.

\section{Influence of the solvent model}

Two well-known SEI-forming additives of LIBs, EC and DTD, were chosen for study, and selected molecular properties of those additives were analyzed for different dielectric constants using the C-PCM, and the results were compared with those from vacuum computations (Table 1). Upon shifting from vacuum to solution, larger dipole moments were observed (a result of the polarization of the solute by the solvent $[66,67])$, and a linear relationship was seen (Fig. 3a). In addition, a small increase in the HOMOLUMO gap was observed. This was mostly an effect of an increased LUMO rather than a decreased HOMO, as the latter is quite insensitive to solvation (Fig. 3c, d). Similar dependences were also noted for IP, EA, and $\eta$, as they have the same origin. A significant decrease was observed in the BE, which is logical given that solvents facilitate the dissociation of ion pairs: the BEs upon solvation in water were $4-8 \%$ of the BEs in vacuum (Fig. 3b). Since BOB is an anion, it behaved differently; its data points were out of range of the plots presented in Fig. 3.

Considerable changes in predicted reduction potentials were observed due to the shifted LUMO levels and the influence of the solvent. Indeed, the directions of the changes depended on the approach applied. Neglecting the lithium cation (a) resulted in very low reduction potentials in the gas phase. Introducing $\mathrm{Li}^{+}$into the system (b, c), even when it was 
Table 2 Reduction potentials predicted using the three different thermodynamic cycles (a), (b), and (c) and various functionals; all values shown in the table are in $\mathrm{V}$ vs. $\mathrm{Li}^{+} / \mathrm{Li}^{0}$

\begin{tabular}{|c|c|c|c|c|c|c|c|c|c|c|c|c|c|}
\hline Additive & Exp. & Thermodynamic cycle & $\mathrm{HF}$ & mPW2PLYP & TPSSH & B2PLYP & B3LYP & VSXC & PBE0 & M062X & M06L & M11 & MN12L \\
\hline \multirow[t]{3}{*}{$\mathrm{EC}^{\mathrm{a}}$} & $1.36[69]$ & $\mathrm{a}$ & 1.05 & 1.30 & 1.32 & 1.29 & 1.49 & 1.62 & 1.26 & 1.27 & 1.28 & 1.38 & 1.01 \\
\hline & & $\mathrm{b}$ & 1.50 & 1.78 & 1.63 & 1.73 & 1.80 & 2.07 & 1.71 & 1.63 & 1.43 & 1.86 & 1.35 \\
\hline & & $\mathrm{c}$ & 1.37 & 1.65 & 1.62 & 1.63 & 1.79 & 1.99 & 1.61 & 1.64 & 1.59 & 1.76 & 1.34 \\
\hline \multirow[t]{3}{*}{ FEC $^{\mathrm{a}}$} & $0.7[70]$ & $\mathrm{a}$ & 0.48 & 0.82 & 0.80 & 0.81 & 1.05 & 1.44 & 0.71 & 0.68 & 0.78 & 1.03 & 0.59 \\
\hline & & $\mathrm{b}$ & 0.65 & 0.99 & 0.85 & 0.99 & 1.08 & 1.57 & 0.92 & 0.77 & 0.85 & 1.21 & 0.85 \\
\hline & & $\mathrm{c}$ & 0.57 & 0.90 & 0.88 & 0.93 & 1.11 & 1.54 & 0.86 & 0.79 & 0.89 & 1.14 & 0.71 \\
\hline \multirow[t]{3}{*}{$\mathrm{VC}^{\mathrm{a}}$} & 1.40 [69] & $\mathrm{a}$ & 0.82 & 0.86 & 0.87 & 0.84 & 1.07 & 1.11 & 0.80 & 0.87 & 0.91 & 0.96 & 0.61 \\
\hline & & $\mathrm{b}$ & 1.18 & 1.21 & 1.07 & 1.15 & 1.27 & 1.45 & 1.12 & 1.15 & 1.09 & 1.15 & 0.82 \\
\hline & & $\mathrm{c}$ & 1.10 & 1.14 & 1.12 & 1.11 & 1.32 & 1.42 & 1.07 & 1.20 & 1.13 & 1.22 & 0.85 \\
\hline \multirow[t]{3}{*}{$\mathrm{VEC}^{\mathrm{a}}$} & $2.2[28]$ & $\mathrm{a}$ & 1.75 & 1.86 & 1.93 & 1.85 & 2.13 & 2.30 & 1.88 & 1.83 & 1.93 & 2.00 & 1.67 \\
\hline & & $\mathrm{b}$ & 2.20 & 2.31 & 2.26 & 2.27 & 2.45 & 2.77 & 2.31 & 2.18 & 2.24 & 2.46 & 1.99 \\
\hline & & $\mathrm{c}$ & 2.07 & 2.18 & 2.25 & 2.17 & 2.45 & 2.69 & 2.22 & 2.18 & 2.22 & 2.18 & 1.99 \\
\hline \multirow[t]{3}{*}{$\mathrm{PMC}^{\mathrm{a}}$} & $0.83[16]$ & $\mathrm{a}$ & 1.39 & 1.39 & 1.39 & 1.51 & 1.66 & 1.52 & 1.42 & 1.25 & 1.21 & 1.23 & 0.98 \\
\hline & & $\mathrm{b}$ & 1.88 & 1.87 & 1.76 & 1.82 & 1.97 & 1.93 & 1.71 & 1.61 & 1.54 & 1.63 & 1.21 \\
\hline & & $\mathrm{c}$ & 1.80 & 1.78 & 1.78 & 1.75 & 1.99 & 1.88 & 1.77 & 1.64 & 1.45 & 1.55 & 1.24 \\
\hline \multirow[t]{3}{*}{ VA } & 0.88 [16] & $\mathrm{a}$ & -1.28 & 0.07 & 0.25 & 0.07 & 0.30 & 0.27 & 0.19 & 0.16 & 0.07 & 0.23 & -0.06 \\
\hline & & $\mathrm{b}$ & -0.04 & 0.59 & 0.61 & 0.54 & 0.67 & 0.64 & 0.67 & 0.56 & 0.40 & 0.76 & 0.30 \\
\hline & & $\mathrm{c}$ & -0.10 & 0.51 & 0.64 & 0.49 & 0.70 & 0.60 & 0.61 & 0.55 & 0.45 & 0.72 & 0.33 \\
\hline \multirow[t]{3}{*}{ VP } & 0.8 [49] & $\mathrm{a}$ & -0.08 & 0.56 & 0.74 & 0.55 & 0.79 & 0.74 & 0.78 & 0.72 & 0.75 & 0.76 & 0.63 \\
\hline & & $\mathrm{b}$ & 0.36 & 0.91 & 1.00 & 0.89 & 1.04 & 1.11 & 1.11 & 0.99 & 0.98 & 1.10 & 0.83 \\
\hline & & $\mathrm{c}$ & 0.40 & 0.89 & 1.08 & 0.90 & 1.13 & 1.12 & 1.13 & 1.08 & 1.06 & 1.12 & 0.95 \\
\hline \multirow[t]{3}{*}{$\mathrm{ES}^{\mathrm{a}}$} & $2.1[71]$ & $\mathrm{a}$ & 0.88 & 1.45 & 1.56 & 1.46 & 1.75 & 1.88 & 1.46 & 1.40 & 1.54 & 1.54 & 1.31 \\
\hline & & $\mathrm{b}$ & 1.67 & 2.16 & 2.04 & 2.12 & 2.28 & 2.58 & 2.07 & 2.03 & 2.00 & 2.25 & 1.79 \\
\hline & & $\mathrm{c}$ & 1.53 & 2.08 & 2.09 & 2.07 & 2.33 & 2.57 & 2.02 & 2.04 & 2.05 & 2.17 & 1.82 \\
\hline \multirow[t]{3}{*}{$\mathrm{DTD}^{\mathrm{a}}$} & 2.13 [19] & $\mathrm{a}$ & -1.01 & 2.02 & 2.18 & 1.95 & 2.41 & 2.76 & 1.97 & 1.94 & 2.11 & 2.08 & 1.63 \\
\hline & & $\mathrm{b}$ & 2.36 & 2.31 & 2.31 & 2.28 & 2.57 & 2.91 & 2.23 & 2.19 & 2.20 & 2.41 & 1.81 \\
\hline & & $\mathrm{c}$ & 2.29 & 2.23 & 2.39 & 2.25 & 2.62 & 2.92 & 2.23 & 2.24 & 2.25 & 2.39 & 1.90 \\
\hline \multirow[t]{3}{*}{ BOB } & 1.8 [72] & $\mathrm{a}$ & 0.40 & 1.13 & 1.31 & 1.10 & 1.39 & 1.26 & 1.29 & 1.28 & 1.09 & 1.42 & 0.99 \\
\hline & & $\mathrm{b}$ & 0.88 & 1.61 & 1.67 & 1.55 & 1.74 & 1.82 & 1.75 & 1.72 & 1.47 & 1.96 & 1.46 \\
\hline & & $\mathrm{c}$ & 0.77 & 1.48 & 1.65 & 1.44 & 1.76 & 1.65 & 1.65 & 1.70 & 1.45 & 1.85 & 1.44 \\
\hline \multirow{3}{*}{\multicolumn{2}{|c|}{ Standard deviation }} & $\mathrm{a}$ & 1.41 & 0.48 & 0.40 & 0.51 & 0.41 & 0.48 & 0.45 & 0.44 & 0.44 & 0.37 & 0.59 \\
\hline & & $\mathrm{b}$ & 0.57 & 0.39 & 0.35 & 0.38 & 0.45 & 0.62 & 0.34 & 0.30 & 0.32 & 0.39 & 0.35 \\
\hline & & $\mathrm{c}$ & 0.60 & 0.37 & 0.36 & 0.37 & 0.47 & 0.59 & 0.36 & 0.31 & 0.31 & 0.33 & 0.33 \\
\hline \multirow{3}{*}{\multicolumn{2}{|c|}{ Average deviation }} & $\mathrm{a}$ & -0.98 & -0.27 & -0.19 & -0.28 & -0.02 & 0.07 & -0.24 & -0.28 & -0.25 & -0.16 & -0.48 \\
\hline & & $\mathrm{b}$ & -0.16 & 0.15 & 0.10 & 0.11 & 0.27 & 0.47 & 0.14 & 0.06 & 0.00 & 0.26 & -0.18 \\
\hline & & $\mathrm{c}$ & -0.24 & 0.06 & 0.13 & 0.05 & 0.30 & 0.42 & 0.10 & 0.08 & 0.03 & 0.19 & -0.16 \\
\hline
\end{tabular}

${ }^{a} \mathrm{~A}$ chemical bond is broken during the reduction

only in present in its reduced form, increased the reduction potentials. When solvent effects were taken into account, the predicted reduction potentials moved even closer to the experimentally observed values, so this is necessary for any accurate quantitative prediction of $E_{\text {red }}$. The results for different solvents (i.e., dielectric constants) show that varying the dielectric constant only had a significant impact at low values of this constant [68]; the effect of any increase in the constant was minimal when $r$ was greater than approximately 20 . Thus, water - the best-parameterized solvent — can be used as a decent approximation for all solvents with $\mathrm{r}>20$ [34], so water was used as the solvent in all subsequent calculations.

\section{DFT functional and basis-set benchmarking}

The reduction potential is the most important parameter that determines if and when a given compound can be used as an SEI-forming additive. Thus, we calibrated the computational method against experimental reduction potential data from electrochemical studies [16, 19, 28, 49, 69-72]. To determine 
(a)

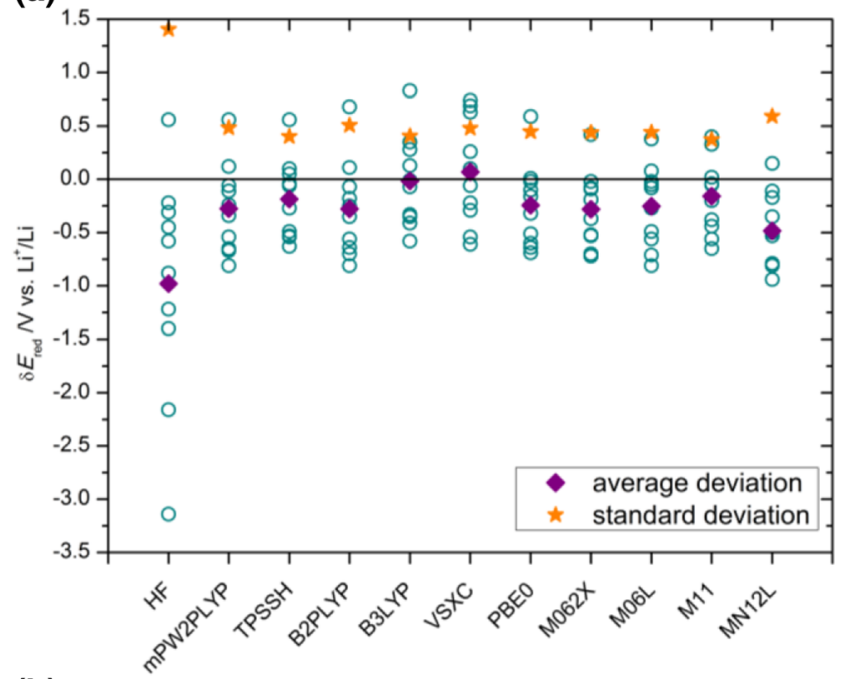

(b)

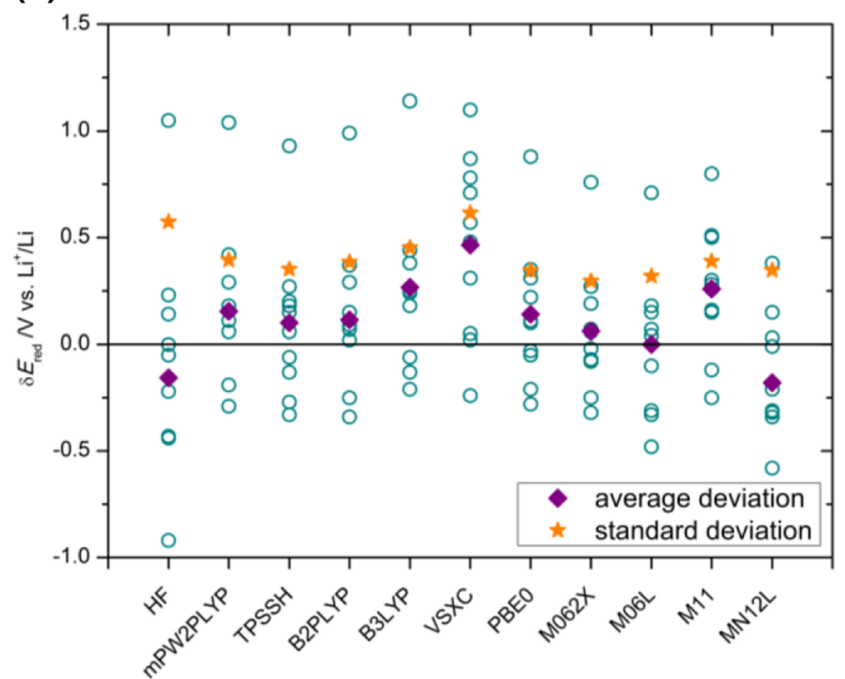

(c)

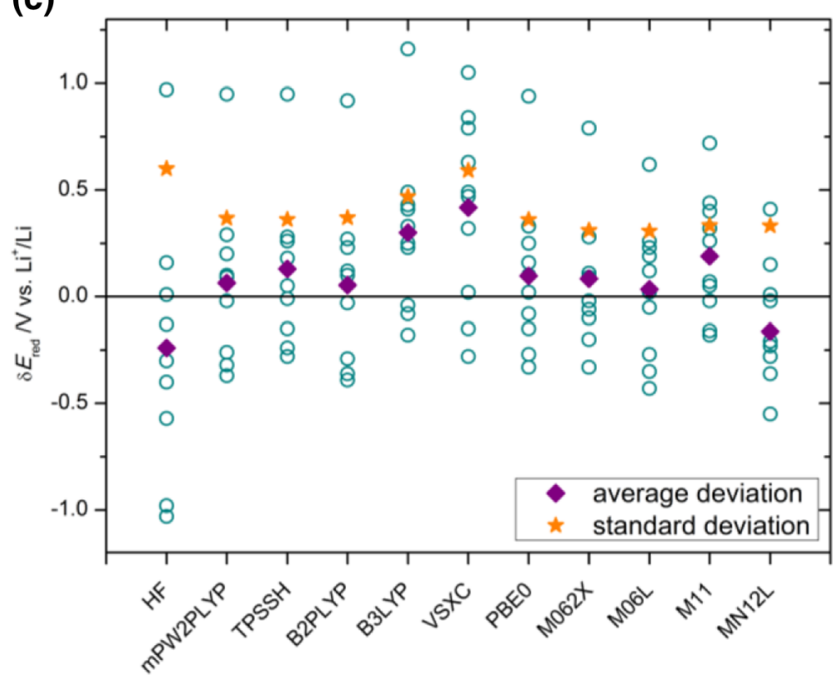

Fig. 4a-c Deviation, $\delta E_{\text {red }}$, of the reduction potential predicted using thermodynamic cycle (a), (b), or (c) (plots a-c, respectively) and each DFT functional from the corresponding experimental value. Average and standard deviations are also shown
Table 3 Reduction potentials obtained using thermodynamic cycle (b) and various functionals and basis sets; all values are in $\mathrm{V} v \mathrm{vs}^{\mathrm{L}} \mathrm{Li}^{+} / \mathrm{Li}^{0}$

\begin{tabular}{|c|c|c|c|c|c|c|}
\hline Additive & Exp. & Basis set & M06-2X & M06L & M11 & MN12L \\
\hline \multirow[t]{4}{*}{$\mathrm{EC}^{*}$} & \multirow[t]{4}{*}{1.36} & $6-311++\mathrm{G}^{* *}$ & 1.63 & 1.43 & 1.86 & 1.35 \\
\hline & & def2-TVPD & 1.66 & 1.45 & 1.78 & 1.25 \\
\hline & & aug-pcseg-2 & 1.68 & 1.44 & 1.80 & 1.30 \\
\hline & & aug-cc-pVTZ & 1.59 & 1.49 & 1.64 & 1.18 \\
\hline \multirow[t]{4}{*}{ FEC* } & \multirow[t]{4}{*}{0.7} & $6-311++\mathrm{G}^{* *}$ & 0.77 & 0.85 & 1.21 & 0.85 \\
\hline & & def2-TVPD & 0.72 & 0.68 & 1.00 & 0.62 \\
\hline & & aug-pcseg-2 & 0.72 & 0.57 & 0.98 & 0.38 \\
\hline & & aug-cc-pVTZ & 0.72 & 0.72 & 1.02 & 0.63 \\
\hline \multirow[t]{4}{*}{$\mathrm{VC}^{*}$} & \multirow[t]{4}{*}{1.40} & $6-311++\mathrm{G}^{* *}$ & 1.15 & 1.09 & 1.15 & 0.82 \\
\hline & & def2-TVPD & 1.09 & 0.91 & 1.19 & 0.65 \\
\hline & & aug-pcseg-2 & 1.10 & 0.90 & 1.21 & 0.72 \\
\hline & & aug-cc-pVTZ & 1.06 & 0.96 & 1.08 & 0.59 \\
\hline \multirow[t]{4}{*}{ VEC* } & \multirow[t]{4}{*}{2.2} & $6-311++\mathrm{G}^{* *}$ & 2.18 & 2.24 & 2.46 & 1.99 \\
\hline & & def2-TVPD & 2.19 & 2.13 & 2.40 & 1.86 \\
\hline & & aug-pcseg-2 & 2.22 & 2.12 & 2.43 & 1.92 \\
\hline & & aug-cc-pVTZ & 2.13 & 2.14 & 2.24 & 1.79 \\
\hline \multirow[t]{4}{*}{ PMC* } & \multirow[t]{4}{*}{0.83} & $6-311++\mathrm{G}^{* *}$ & 1.59 & 1.54 & 1.63 & 1.21 \\
\hline & & def2-TVPD & 1.39 & 1.21 & 1.49 & 1.28 \\
\hline & & aug-pcseg-2 & 1.46 & 1.30 & 1.52 & 1.36 \\
\hline & & aug-cc-pVTZ & 1.49 & 1.30 & 1.44 & 1.36 \\
\hline \multirow[t]{4}{*}{ VA } & \multirow[t]{4}{*}{0.88} & $6-311++\mathrm{G}^{* *}$ & 0.56 & 0.40 & 0.76 & 0.30 \\
\hline & & def2-TVPD & 0.61 & 0.29 & 0.78 & 0.23 \\
\hline & & aug-pcseg-2 & 0.31 & 0.15 & 0.37 & 0.21 \\
\hline & & aug-cc-pVTZ & 0.54 & 0.37 & 0.62 & 0.23 \\
\hline \multirow[t]{4}{*}{ VP } & \multirow[t]{4}{*}{0.8} & $6-311++\mathrm{G}^{* *}$ & 0.99 & 0.98 & 1.10 & 0.83 \\
\hline & & def2-TVPD & 1.04 & 0.89 & 1.13 & 0.81 \\
\hline & & aug-pcseg-2 & 1.05 & 0.90 & 1.15 & 0.88 \\
\hline & & aug-cc-pVTZ & 0.94 & 0.84 & 0.94 & 0.69 \\
\hline \multirow[t]{4}{*}{ ES* } & \multirow[t]{4}{*}{2.1} & $6-311++\mathrm{G}^{* *}$ & 2.03 & 2.00 & 2.25 & 1.79 \\
\hline & & def2-TVPD & 1.65 & 1.50 & 1.82 & 1.20 \\
\hline & & aug-pcseg-2 & 1.70 & 1.54 & 1.86 & 1.30 \\
\hline & & aug-cc-pVTZ & 1.80 & 1.75 & 1.91 & 1.44 \\
\hline \multirow[t]{4}{*}{ DTD* } & \multirow[t]{4}{*}{2.13} & $6-311++\mathrm{G}^{* *}$ & 2.19 & 2.20 & 2.41 & 1.81 \\
\hline & & def2-TVPD & 1.50 & 1.37 & 1.67 & 0.94 \\
\hline & & aug-pcseg-2 & 1.62 & 1.46 & 1.73 & 1.09 \\
\hline & & aug-cc-pVTZ & 1.79 & 1.79 & 1.86 & 1.24 \\
\hline \multirow[t]{4}{*}{ BOB } & \multirow[t]{4}{*}{1.8} & $6-311++\mathrm{G}^{* *}$ & 1.72 & 1.47 & 1.96 & 1.46 \\
\hline & & def2-TVPD & 1.80 & 1.40 & 1.96 & 1.37 \\
\hline & & aug-pcseg-2 & 1.72 & 1.31 & 1.83 & 1.30 \\
\hline & & aug-cc-pVTZ & 1.71 & 1.40 & 1.76 & 1.30 \\
\hline \multirow{4}{*}{\multicolumn{2}{|c|}{ Standard deviation }} & $6-311++\mathrm{G}^{* *}$ & 0.30 & 0.32 & 0.39 & 0.35 \\
\hline & & def2-TVPD & 0.35 & 0.42 & 0.35 & 0.60 \\
\hline & & aug-pcseg-2 & 0.34 & 0.42 & 0.34 & 0.56 \\
\hline & & aug-cc-pVTZ & 0.28 & 0.34 & 0.30 & 0.49 \\
\hline Average d & viation & $6-311++\mathrm{G}^{* *}$ & 0.06 & 0.00 & 0.26 & -0.18 \\
\hline & & def2-TVPD & -0.05 & -0.23 & 0.11 & -0.39 \\
\hline & & aug-pcseg-2 & -0.03 & -0.22 & 0.11 & -0.36 \\
\hline & & aug-cc-pVTZ & 0.03 & -0.14 & 0.11 & -0.29 \\
\hline
\end{tabular}


(a)

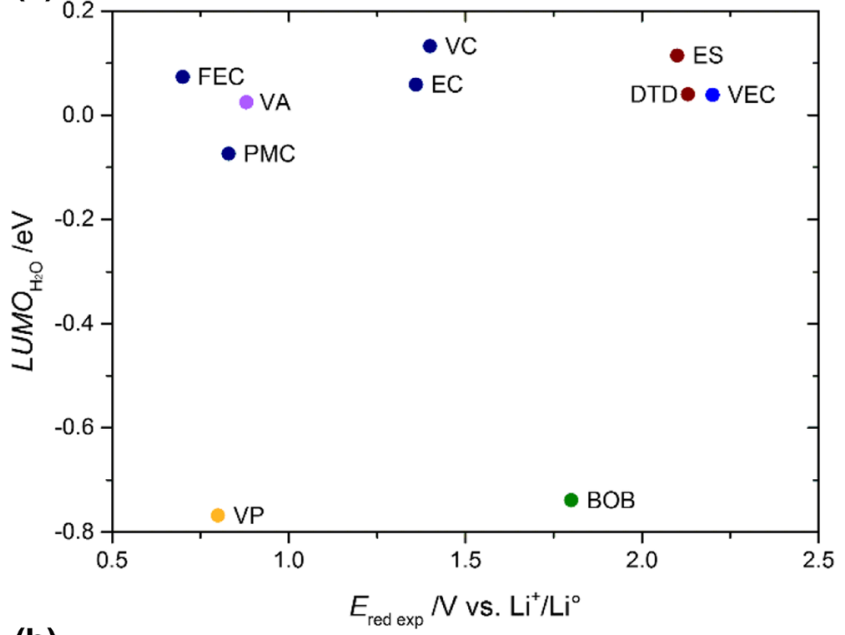

(b)

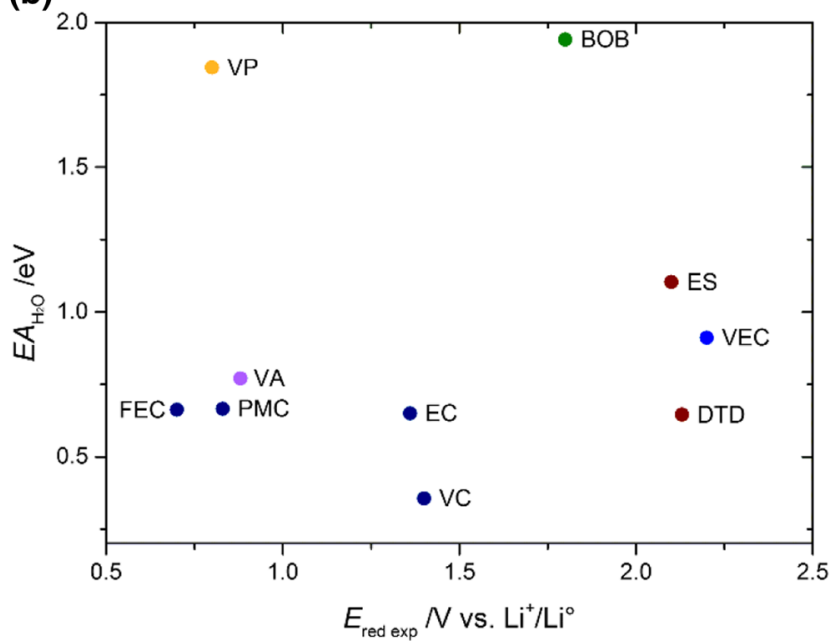

Fig. 5a-b Relationship between the experimental reduction potential and $\mathbf{a}$ the LUMO energy or $\mathbf{b}$ the EA (both obtained using C-PCM M06-2X/6-311++G(d,p))

the best DFT functional, a Pople basis set was used: 6-311++ $\mathrm{G}(\mathrm{d}, \mathrm{p})$. Analysis of the three thermodynamic cycles showed that the influence of the lithium cation often had to be considered (Table 2). Lower standard deviations were only obtained without $\mathrm{Li}^{+}$(i.e., with thermodynamic cycle (a)) when the B3LYP and VSXC functionals were applied. For most methods, the difference between the results obtained using cycles (b) and (c) was very small. To further compare the different methods, the averages and standard deviations obtained using the computational method with various functionals were compared to the corresponding experimental data (Fig. 4). Overall, the M06-2X functional was found to be the best performer, although the other functionals of the Minnesota family (M06L, M11, and MN12L) also provided good results. This is consistent with other reported studies that have benchmarked the DFT prediction of redox properties against highly accurate wavefunction methods [42-45].

Based on the Minnesota family of DFT functionals, the impact of the type of basis set used was examined using cycle (b) (Table 3). The standard deviations obtained with the various the basis sets considered confirmed that M06-2X was the best functional. The popular $6-311++G^{* *}$ basis set gave quite good results compared to the other larger and more advanced basis sets; only the Dunning basis set, aug-cc-pVTZ, provided data that were in better agreement with the experimental data. The Dunning basis set is, however, computationally much more expensive; 46 basis functions are used for each first-row atom, while all other basis sets comprise 22-24 basis functions. Hence, due to its combination of accuracy and efficiency, we chose the Pople basis set $6-311++\mathrm{G}(\mathrm{d}, \mathrm{p})$ for subsequent use.

\section{Descriptor search}

To facilitate the rapid screening of SEI-forming additives, it is advisable to find simple parameters that can easily be calculated for a large number of molecules. The most important properties should be the LUMO energy and the EA; however, based on our analysis (Fig. 5, Table 4), there were no significant trends in these properties. Therefore, descriptors are perhaps more suited to assessing the impact of small changes in the molecular structure, as already reported [73]. Comparisons of completely different molecules appear to be difficult when using a theoretical method that has been simplified by ignoring geometry relaxation, cation interactions, and so on.

Useful information can be obtained by analyzing the chemical hardness, which — besides the HSAB concept [74] - is a viable measure of the tendency of a molecule to donate/accept an electron to/from an electrode. As a soft molecule can easily accept an electron and its reduced form is quite stable, the reduction of hard molecules immediately causes significant changes in geometry (e.g., bond cleavage). This is an important consideration when attempting to predict $E_{\text {red }}$, as it requires the correct definition of the electrode reaction. As noted in Tables 2 and 3, for seven of the studied compounds, the cleavage of a chemical bond must occur to theoretically obtain reduction potentials similar to the experimentally derived values. It is very difficult to determine/guess if bond breaking should be considered to be part of the process that occurs at the electrode process for a completely new compound, but we have found that the chemical hardness is a very good descriptor. Additives softer than ca. $3.5 \mathrm{eV}$ have stable reduced states and their path to SEI formation is determined by any electrode process; the electrode has no influence on the observed reduction potential. In contrast, the reduction of compounds harder than ca. $3.5 \mathrm{eV}$ induces significant structural changes during the initial electrode-controlled process.

\section{Conclusions}

Based on the analysis of ten SEI-forming compounds, we were able to find the most efficient procedure to predict their reduction behavior. The application of an implicit solvent was found to be 
Table 4 Dipole moments, HOMO and LUMO energies, ionization potentials, electron affinities, and binding energies to lithium cations as obtained using C-PCM M06-2X/6-311++G(d,p)

\begin{tabular}{llllllll}
\hline Additive & $\mu(\mathrm{D})$ & HOMO $(\mathrm{eV})$ & LUMO $(\mathrm{eV})$ & $\mathrm{IP}(\mathrm{eV})$ & $\mathrm{EA}(\mathrm{eV})$ & $\eta(\mathrm{eV})$ & $\mathrm{BE}\left(\mathrm{kJ} \mathrm{mol}^{-1}\right)$ \\
\hline EC & 7.33 & -10.62 & 0.06 & 9.15 & 0.43 & 4.36 & 16.0 \\
FEC & 6.59 & -11.02 & 0.07 & 9.55 & 0.66 & 4.44 & 11.4 \\
VC & 6.27 & -8.74 & 0.13 & 7.62 & 0.36 & 3.63 & 14.1 \\
VEC & 7.63 & -9.42 & 0.04 & 8.09 & 0.91 & 3.59 & 16.7 \\
PMC & 0.49 & -9.58 & -0.07 & 8.39 & 0.67 & 3.86 & 10.2 \\
VA & 2.31 & -8.74 & 0.03 & 7.42 & 0.77 & 3.33 & 13.0 \\
VP & 2.82 & -8.07 & -0.77 & 6.96 & 1.84 & 2.56 & 19.1 \\
ES & 5.19 & -9.92 & 0.11 & 8.57 & 1.10 & 3.73 & 15.3 \\
DTD & 7.98 & -10.77 & 0.04 & 9.55 & 0.65 & 4.45 & 7.4 \\
BOB & 0.00 & -9.71 & -0.74 & 8.80 & 1.94 & 3.43 & 16.1 \\
\hline
\end{tabular}

necessary for any accurate prediction, but solvent permeability was not a crucial influence when it was $>20$. In addition, the lithium cation was observed to have a crucial influence on the thermodynamic cycle. Comparison of different methods and basis sets showed that functionals from the Minnesota family, especially M06-2X, were the best tools to describe the reduction potential. The popular Pople basis set $6-311++G(d, p)$ seems to be suitable, even though slightly better results can be obtained from the larger - and hence computationally more expensiveDunning basis set aug-cc-pVTZ. Analysis of popular descriptors revealed that it is impossible to assess the reduction potential based on simple parameters such as the LUMO energy in a wide range of chemical compounds; such screening is only useful when considering compounds that show only small differences in structure. The chemical hardness was, however, found to be an useful property for predicting changes during the electrode process, even for very different chemistries.

Acknowledgements All calculations were carried out at the Wroclaw Centre for Networking and Supercomputing (http://www.wcss.pl), grant no. 346. Support from the National Science Center of Poland (grant no. 2015/17/N/ST4/03867), the ALISTORE-ERI (for doctoral studies), and the Chalmers Energy Area of Advance (for providing a travel scholarship to Piotr Jankowski) are all gratefully acknowledged. Patrik Johansson acknowledges both the Swedish Energy Agency for a basic research grant via the Swedish Research Council, as well as the continuous support provided by many of the Chalmers Areas of Advance: Energy, Materials Science, and Transport.

Open Access This article is distributed under the terms of the Creative Commons Attribution 4.0 International License (http:// creativecommons.org/licenses/by/4.0/), which permits unrestricted use, distribution, and reproduction in any medium, provided you give appropriate credit to the original author(s) and the source, provide a link to the Creative Commons license, and indicate if changes were made.

\section{References}

1. Nishi Y (2001) J Power Sources 100:101-106

2. Armand M, Tarascon JM (2008) Nature 451:652-657

3. Scrosati B, Hassoun J, Sun YK (2011) Energy Environ Sci 4:32873295
4. Scrosati B, Garche J (2010) J Power Sources 195:2419-2430

5. Nitta N, Wu F, Lee JT, Yushin G (2014) Mater Today 18:252-264

6. Aurbach D, Ein-Eli Y (1995) J Electrochem Soc 142:1746-1752

7. Terada Y, Yasaka K, Nishikawa F, Konishi T, Yoshio M, Nakai I (2001) J Solid State Chem 156:286-291

8. Haregewoin AM, Wotangoa AS, Hwang BJ (2016) Energy Environ Sci 9:1955-1988

9. Aurbach D, Gamolsky K, Markovsky B, Gofer Y, Schmidt M, Heider U (2002) Electrochim Acta 47:1423-1439

10. Hu Y, Kong W, Li H, Huang X, Chen L (2004) Electrochem Commun 6:126-131

11. Ota H, Sakata Y, Inoue A, Yamahuchi S (2004) J Electrochem Soc 151:A1659-A1669

12. Sasaki T, Abe T, Iriyama Y, Inaba M, Ogumi Z (2005) J Electrochem Soc 152:A2046-A2050

13. Contestabile M, Morselli M, Paraventi R, Neat RJ (2003) J Power Sources 119-121:943-947

14. Li J, Yao W, Meng YS, Yang Y (2008) J Phys Chem C 112:1255012556

15. Abe K, Hattori T, Kawabe K, Ushigoe Y, Uoshitake H (2007) J Electrochem Soc 154:A810

16. Abe K, Miyoshi K, Hattori T, Ushigoe Y, Yoshitake H (2008) J Power Sources 184:449-455

17. Choi NS, Yew KH, Lee KY, Sung M, Kim H, Kim SS (2006) J Power Sources 161:1254-1259

18. Shu ZX, McMillan R, Murray JJ, Davidson I (1996) J Electrochem Soc 143:2230-2235

19. Janssen P, Schmitz R, Muller R, Isken P, Lex-Balducci A, Schreiner C, Winter M, Cekvic-Laskovic I, Schmitz R (2004) J Power Sources 125:101-106

20. Sano A, Maruyama S (2009) J Power Sources 192:714-718

21. Leung K (2013) Chem Phys Lett 568-569:1-8

22. Endo E, Ata M, Tanaka K, Sekai K (1998) J Electrochem Soc 145: 3757-3764

23. Li T, Balbuena PB (2000) Chem Phys Lett 317:421-429

24. Wang Y, Balbuena PB (2002) J Phys Chem B 106:4486-4495

25. Wang Y, Nakamura S, Ue M, Balbuena PB (2001) J Am Chem Soc 123:11708-11718

26. Han YK, Lee SU (2004) Theor Chem Accounts 112:106-112

27. Wang Y, Nakamura S, Tasaki K, Balbuena PB (2002) J Am Chem Soc 124:4408-4421

28. Vollmer JM, Curtiss LA, Vissers DR, Amine K (2004) J Electrochem Soc 151:A178-A183

29. Leggesse EG, Jiang JC (2012) J Phys Chem A 116:11025-11033

30. Han YK, Lee SU, Ok JH, Cho JJ, Kim HJ (2002) Chem Phys Lett 360:359-366

31. Leggesse EG, Jiang JC (2012) RSC Adv 2:5439-5446

32. Husch T, Korth M (2015) Phys Chem Chem Phys 17:22799-22808 
33. Cheng L, Assary RS, Qu X, Jain A, Ong SP, Rajput NN, Person K, Curtiss LA (2015) J Phys Chem Lett 6:283-291

34. Korth M (2015) Chem Model 11:57-87

35. Halls MD, Tasaki K (2010) J Power Sources 195:1472-1478

36. Park MH, Lee YS, Lee H, Han YK (2011) J Power Sources 196: 5109-5114

37. Johansson P, Scheers J (2014) Prediction of electrolyte and additive electrochemical stabilities. In: Jow TR, Xu K, Borodin O, Ue M (ed) Electrolytes for lithium and lithium-ion batteries. Springer, New York

38. Zhao Y, Schultz NE, Truhlar DG (2005) J Chem Phys 123:194101

39. Zhao Y, Truhlar DG (2008) Theor Chem Accounts 120:215-241

40. Peverati R, Truhlar DG (2011) J Phys Chem Lett 2:2810-2817

41. Peverati R, Truhlar DG (2012) Phys Chem Chem Phys 10:13171

42. Silva PJ, Ramos MJ (2011) Comput Theor Chem 966:120-126

43. Capobianco A, Vekardo A, Peluso A (2015) Comput Theor Chem 1070:68-75

44. Jónsson E, Johansson P (2015) Phys Chem Chem Phys 17:3693703

45. Isegawa M, Neese F, Pantazis DA (2016) J Chem Theory Comput 45:2272-2284

46. Lespes N, Filhol JS (2015) J Chem Theory Comput 11:3375-3382

47. Aurbach D, Gofer Y, Ben-Zion M, Aped P (1992) J Electroanal Chem 339:451-471

48. Haregewoin AM, Leggesse EG, Jiang JC, Wang FM, Hwang BJ, Lin SD (2014) Electrochim Acta 136:274-285

49. Komaba S, Itabashi T, Ohtsuka T, Groult H, Kumagai N, Kaplan B, Yashiro H (2005) J Electrochem Soc 152:A937-A946

50. Frisch MJ, Trucks GW, Schlegel HB, Scuseria GE, Robb MA, Cheeseman JR, Scalmani G, Barone V, Mennucci B, Petersson GA, Nakatsuji H, Caricato M, Li X, Hratchian HP, Izmaylov AF, Bloino J, Zheng G, Sonnenberg JL, Hada M, Ehara M, Toyota K, Fukuda R, Hasegawa J, Ishida M, Nakajima T, Honda Y, Kitao O, Nakai H, Vreven T, Montgomery JA Jr, Peralta JE, Ogliaro F, Bearpark M, Heyd JJ, Brothers E, Kudin KN, Staroverov VN, Kobayashi R, Normand J, Raghavachari K, Rendell A, Burant JC, Iyengar SS, Tomasi J, Cossi M, Rega N, Millam JM, Klene M, Knox JE, Cross JB, Bakken V, Adamo C, Jaramillo J, Gomperts R, Stratmann RE, Yazyev O, Austin AJ, Cammi R, Pomelli C, Ochterski JW, Martin RL, Morokuma K, Zakrzewski VG, Voth
GA, Salvador P, Dannenberg JJ, Dapprich S, Daniels AD, Farkas Ö, Foresman JB, Ortiz JV, Cioslowski J, Fox DJ (2009) Gaussian 09, revision E.01. Gaussian, Inc., Wallingford

51. Schwabe T, Grimme S (2006) Phys Chem Chem Phys 8:4398

52. Tao JM, Perdew JP, Staroverov VN, Scuseria GE (2003) Phys Rev Lett 91:146401

53. Grimme S (2006) J Chem Phys 124:034108

54. Becke AD (1993) J Chem Phys 98:5648-5652

55. Van Voorhis T, Scuseria GE (1998) J Chem Phys 109:400-410

56. Adamo C, Barone V (1999) J Chem Phys 110:6158-6169

57. Zhao Y, Truhlar DG (2006) J Chem Phys 125:194101

58. Krishnan R, Binkley JS, Seeger R, Pople JA (1980) J Chem Phys 72:650-654

59. Clark T, Chandrasekhar J, Spitznagel GW, Schleyer PVR (1983) J Comput Chem 4:294-301

60. Rappoport D, Furche F (2010) J Chem Phys 133:134105

61. Buczek A, Kupka T, Broda MA, Żyła A (2016) J Mol Model 22:110

62. Kendall RA, Dunning TH Jr, Harrison RJ (1992) J Chem Phys 96: 6796-6806

63. Barone V, Cossi M, Tomasi J (1998) J Comput Chem 19:404-417

64. Wang Y, Balbuena PB (2005) Int J Quantum Chem 425:724-733

65. Trasatti S (1986) Pure Appl Chem 58:955-966

66. Cramer CJ, Truhlar DG (1999) Chem Rev 99:2161-2200

67. Padmanabhan J, Parthasarathi R, Sarkar U, Subramanian V, Chattaraj PK (2004) Chem Phys Lett 383:122-128

68. Han YK, Lee K, Jung SC, Huk YS (2014) Comput Theor Chem 1031:64-68

69. Zhang X, Kostecki R, Richardson TJ, Pugh JK, Ross PN (2001) J Electrochem Soc 148:A1341-A1345

70. Profatilova IA, Kim SS, Choi NS (2009) Electrochim Acta 54: 4445-4450

71. Wrodnigg GH, Basenhard JO, Winter M (1999) J Electrochem Soc 146:470-472

72. Panitz JC, Wietelmann U, Wachtler M, Strobele S, WohlfahrtMehrens M (2006) J Power Sources 153:396-401

73. Han YH, Moon Y, Lee K, Huh YS (2014) Curr Appl Phys 14:897900

74. Pearson RG (1968) J Chem Educ 45:581-586 